\title{
A Novel Monthly Dosing Regimen of Risedronate for the Treatment of Postmenopausal Osteoporosis: 2-Year Data
}

\author{
Michael R. McClung • Claude-Laurent Benhamou • Zulema Man • \\ Witold Tlustochowicz - Jose R. Zanchetta - Rachelle Eusebio - Ana M. Balske • \\ Ellen Matzkin • Wojciech P. Olszynski • Robert Recker • Pierre D. Delmas
}

Received: 29 June 2012/Accepted: 17 October 2012/Published online: 13 November 2012

(C) The Author(s) 2012. This article is published with open access at Springerlink.com

\begin{abstract}
This 2-year trial evaluated the efficacy and tolerability of a monthly oral regimen of risedronate. Postmenopausal women with osteoporosis were randomly assigned to double-blind treatment with risedronate $75 \mathrm{mg}$ on 2 consecutive days each month (2CDM) or $5 \mathrm{mg}$ daily. The primary end point was the percentage change from baseline in lumbar spine bone mineral density (BMD) at
\end{abstract}

P.D. Delmas-(deceased)

M. R. McClung is a consultant and/or speaker for Amgen, Lilly, Merck, Novartis, and Warner-Chilcott. C. L. Benhamou is a consultant and/or speaker for Amgen, Merck, Novartis, Roche, and Servier; he also received funding from Amgen, Servier, Roche, and UCB Pharma. Z. Man receives consulting fees as member of Novartis' Steering Committee, and for Advisory Boards of GSK and sanofi-aventis; is a speaker for Novartis, Roche, sanofi-aventis and Servier; and also received grant/research support from Amgen, Eli Lilly, Merck, Novartis, NPS, GSK, Roche, sanofi-aventis, Servier and Procter and Gamble. W. Tlustochowicz is a speaker for Amgen, Roche, Novartis and sanofi-aventis. J. R. Zanchetta receives consulting fees and is a member of Advisory Boards for Amgen, Eli Lilly, GSK, Merck, Pfizer, and Servier; he has also received grant/ research support from Amgen, Eli Lilly, Merck, Pfizer, GSK, and Procter and Gamble. R.A Eusebio is a full-time employee of and owns stocks in Procter and Gamble Company. A. M. Balske is an employee of Procter and Gamble. E. Matzkin: no disclosures. W. P. Olszynski is a consultant for the Canadian Arthritis Network, Canadian Rheumatology Association, CaMos, Osteoporosis Canada, International Society of Clinical Densitometry, Pharmaceutical Companies Abbott Laboratories Ltd., Amgen Canada, Aventis Pharma Inc., Eli Lilly Canada Inc., GSK Inc., Hoffman-LaRoche Ltd., Merck Canada Inc., Novartis Pharmaceutical Canada Inc., Pfizer Canada Inc., Quality Council of Saskatchewan, Saskatoon Health Region, and University of Saskatchewan. R.R. Recker is a paid consultant for Merck, Lilly, Wyeth, Procter and Gamble, Amgen, Roche, GlaxoSmithKline, Novartis, and NPS Allelix; and received grant/research support from Merck, Lilly, Wyeth, Procter and Gamble, Amgen, Roche, GlaxoSmithKline, Novartis, NPS Allelix, and sanofi-aventis through grants to his institution.
12 months. Secondary end points included the change in BMD of the lumbar spine and proximal femur and in bone turnover markers as well as the number of subjects with at least one new vertebral fracture over 24 months. Among 1,229 patients who were randomized and received at least one dose of risedronate, lumbar spine BMD was increased in both treatment groups: mean percentage change from baseline was $4.2 \pm 0.19$ and $4.3 \pm 0.19 \%$ in the $75 \mathrm{mg}$ 2CDM and $5 \mathrm{mg}$ daily groups, respectively, at month 24 . The treatment difference was 0.17 (95\% confidence interval -0.35 to 0.68 ). There were no statistically significant differences between treatment groups on any secondary efficacy parameters. Both treatment regimens were well tolerated. Risedronate $75 \mathrm{mg} 2 \mathrm{CDM}$ was noninferior in BMD efficacy and did not show a difference in tolerability compared to $5 \mathrm{mg}$ daily after 24 months of treatment in women with postmenopausal osteoporosis. This monthly

M. R. McClung ( $₫)$

Oregon Osteoporosis Center, 5050 NE Hoyt Street, Suite 626,

Portland, OR 97213, USA

e-mail: mmcclung@orost.com

C.-L. Benhamou

EA 4708 Orléans University and Orléans Hospital, Orléans,

France

Z. Man

Centro Médico TIEMPO, Buenos Aires, Argentina

W. Tlustochowicz

Klinika Chorob Wewnetrznych i Reumatologii, Centralny

Szpital Kliniczny MON Wojskowy Instytut Medyczny, Warsaw, Poland

J. R. Zanchetta

Instituto de Investigaciones Metabolicas, Buenos Aires, Argentina 
regimen may provide a more convenient dosing schedule to some patients with postmenopausal osteoporosis.

Keywords Bone mineral density - Bone turnover markers · Osteoporosis · Risedronate

\section{Introduction}

Oral bisphosphonates are the most commonly prescribed drugs for the treatment of postmenopausal osteoporosis. Each of the three available oral bisphosphonates was originally developed for daily dosing. However, because the drugs have to be given while fasting, with a 30-60 min interval before the patient may eat, drink beverages other than water, or take other medicines, many patients found daily dosing to be inconvenient. Bisphosphonates bind with variable affinity to bone mineral and reside within the bone matrix for long periods after dosing. The drugs remain active on the surface of bone, providing the opportunity to develop a range of dosing schedules. When given the option of daily dosing or less frequent (weekly or monthly) dosing, most patients chose the latter [1]. Adherence to therapy is modestly improved with weekly or monthly dosing regimens compared with daily dosing [2, 3].

Daily dosing with risedronate, a potent nitrogen-containing bisphosphonate, has been found to reduce the incidence of vertebral, nonvertebral, and hip fracture [4-6]. It was later demonstrated that $35 \mathrm{mg}$ once a week provided similar efficacy, assessed by changes in bone mineral density (BMD), and safety to the daily regimen [7]. Risedronate $75 \mathrm{mg}$ each day for 2 consecutive days a month (2CDM) has also been shown to be an effective treatment regimen for postmenopausal osteoporosis [8]. In that article, the efficacy and safety of risedronate $75 \mathrm{mg}$ 2CDM was compared with the $5 \mathrm{mg}$ daily regimen in postmenopausal women with osteoporosis over a 12-month

R. Eusebio

Procter and Gamble Company, Mason, OH, USA

A. M. Balske

Abbott Laboratories, Abbott Park, Chicago, IL, USA

E. Matzkin

The sanofi-aventis Group, Bridgewater, NJ, USA

W. P. Olszynski

Saskatoon Osteoporosis Center, Sasketoon, SK, Canada

R. Recker

Osteoporosis Research Center, Creighton University, Omaha,

NE, USA

P. D. Delmas

INSERM Research Unit 831, University of Lyon, Lyon, France period. Risedronate $75 \mathrm{mg}$ 2CDM was shown to be noninferior in BMD response and similar in tolerability to the $5 \mathrm{mg}$ daily dosing regimen after 12 months [8]. This report provides the 2-year data from this study and assesses whether 2CDM provides continued efficacy and safety similar to the $5 \mathrm{mg}$ daily regimen in postmenopausal women with osteoporosis during the second year of treatment.

\section{Methods}

\section{Study Design}

Details of the study design, patient population, and inclusion criteria have previously been reported [8]. Briefly, this was a multicenter, double-blind, randomized, active-controlled, parallel-group, noninferiority study designed to compare two oral dosing regimens of risedronate for the treatment of postmenopausal osteoporosis. The trial was conducted in accordance with the guidelines of the International Conference on Harmonization for Good Clinical Practice, and the study protocol was approved by Independent Ethics Committees at each participating study center. The study's ClinicalTrials.gov identifier was NCT00358176.

Subjects

Healthy, ambulatory women who were at least 50 years old and had been postmenopausal for 5 years or more were eligible for inclusion in this study if they had osteoporosis as defined by a lumbar spine $\mathrm{T}$-score of -2.5 or lower or a T-score of -2.0 or lower and at least one prevalent vertebral fracture. Subjects were excluded if they had received any bone active drugs within 3 months of the first dose of the study medication, had a body mass index of $>32 \mathrm{~kg} / \mathrm{m}^{2}$, or had a history of drug or alcohol abuse.

\section{Treatment}

Subjects were randomly assigned in a 1:1 ratio to one of two risedronate oral dosing regimens: $75 \mathrm{mg} 2 \mathrm{CDM}$ or $5 \mathrm{mg}$ daily. Subjects were told to take their medication with water, in an upright position, on an empty stomach in the morning, at least 30 minutes before their first food or drink of the day. Supplementation with $1,000 \mathrm{mg}$ of elemental calcium and 400-800 IU of vitamin D was permitted, depending on supplement availability and customary local practice. Patient compliance with the assigned treatment protocol was determined by tablet counts at every visit. 


\section{Outcome Measures}

Bone mineral density (BMD) of the lumbar spine and total hip was measured by dual energy X-ray absorptiometry (DXA) at baseline and months 6, 12, and 24. All DXA scans were performed using Lunar (General Electric, Madison, WI, USA) and Hologic (Hologic Inc., Waltham, MA, USA) machines with all scans for each subject being acquired on the same machine. SYNARC (SYNARC, San Francisco, CA, USA) performed all DXA analyses and ensured DXA equipment stability throughout the study. Lateral X-rays of the thoracic and lumbar spine were obtained at baseline and at month 24 or at early termination visit. All X-rays were analyzed at the SYNARC central reading facility using a semiquantitative scoring of digitized films. Fasting samples were collected for bone turnover markers (BTMs) including urinary $N$-telopeptide (uNTx) and serum bone-specific alkaline phosphatase (sBAP)

The primary efficacy end point was the mean percentage change from baseline in lumbar spine BMD at month 12. Secondary efficacy measures included the mean percentage change from baseline in lumbar spine BMD at month 24 and end point; mean percentage change from baseline in total hip, femoral neck, and trochanter BMD at month 24 and end point; mean percentage change in UNTx and SBAP at month 24 and end point; the number of subjects with $\geq 1$ new vertebral fracture at month 24 and end point. Month 24 values include only assessments made when subjects returned for the study visit after completing 24 months of therapy. End point values included the 24-month values plus the last results of other subjects for whom 24-month values were not available but who had undergone at least one BMD, bone turnover marker, or spine X-ray assessment performed after taking at least one dose of study drug.

\section{Safety}

A physical examination was performed before treatment and at months 12 and 24. Vital signs and adverse events were assessed and recorded at all scheduled visits. Serum chemistries, including calcium and liver function tests and hematology tests were performed at 6 month intervals and urinalysis was performed annually.

\section{Statistical Analyses}

The primary efficacy analysis was a test of noninferiority comparing the mean percentage change from baseline in lumbar spine BMD in the $75 \mathrm{mg} 2 \mathrm{CDM}$ and $5 \mathrm{mg}$ daily groups after 12 months. Noninferiority was to be declared if the upper bound of the 2-sided $95 \%$ confidence interval (95\% CI) for the treatment difference (5 mg daily minus
$75 \mathrm{mg}$ 2CDM) did not exceed the predefined noninferiority margin of $1.5 \%$. This margin was based on the mean difference in BMD percentage change between $5 \mathrm{mg}$ once daily and placebo $[4,5]$. The primary analysis population was all subjects who were randomized, received at least one dose of study drug, and had evaluable measurements of lumbar spine BMD at both baseline and month 12 . The noninferiority analysis was performed in a similar manner after 24 months. If the upper limit of the $95 \%$ 2-sided confidence interval for the treatment difference obtained from the ANOVA model did not exceed the predefined noninferiority margin of $2.0 \%$, then the $75 \mathrm{mg} 2 \mathrm{CDM}$ regimen would be declared noninferior to the $5 \mathrm{mg}$ daily regimen at month 24 . Investigative centers were pooled by geographic region. An analysis of variance (ANOVA) was performed with treatment and pooled centers as fixed effects and percentage change from baseline in lumbar spine BMD as the response variable. Continuous secondary efficacy variables were analyzed using similar ANOVA methods. Two-sided $95 \%$ CIs were constructed for changes from baseline, between treatment groups, and within treatment groups. No statistical test for superiority of the 2CDM dose to the daily dose of risedronate was performed.

\section{Results}

Subjects

As reported previously [8], a total of 3,027 women were screened at 61 sites in 11 countries, with 1,231 subjects enrolled and randomized for treatment. At least one dose of risedronate was received by 1,229 subjects. Figure 1 illustrates subject disposition throughout the study period.

Demographics of the subjects in each treatment group were similar between the two treatment groups (Table 1); details have previously been reported [8]. Mean age was approximately 65 years, and mean lumbar spine and total hip $\mathrm{T}$-scores were approximately -3.2 and -1.9 , respectively. Approximately $30 \%$ of subjects had at least one prevalent fracture.

Similar proportions of subjects in each study group completed the 24-month study: $476(77 \%)$ in the $75 \mathrm{mg}$ 2CDM group and $467(76 \%)$ in the $5 \mathrm{mg}$ daily group. Mean treatment duration with risedronate was similar for both treatment groups: 625 days for subjects receiving $75 \mathrm{mg}$ 2CDM, and 627 days for subjects receiving $5 \mathrm{mg}$ daily. About $15 \%$ of subjects had withdrawn from the study by 12 months. The reasons for treatment discontinuation over 24 months are summarized in Table 2. The proportion of subjects with over $80 \%$ compliance was $96 \%$ for the $75 \mathrm{mg} 2 \mathrm{CDM}$ group, and $97 \%$ for the $5 \mathrm{mg}$ daily group. 
Fig. 1 Subject disposition. $2 C D M$ two consecutive days each month. One subject in each of the treatment groups missed their month 12 visit but continued on to year 2 . These two subjects were not counted in month 12 visit but were included in the month 24 visit

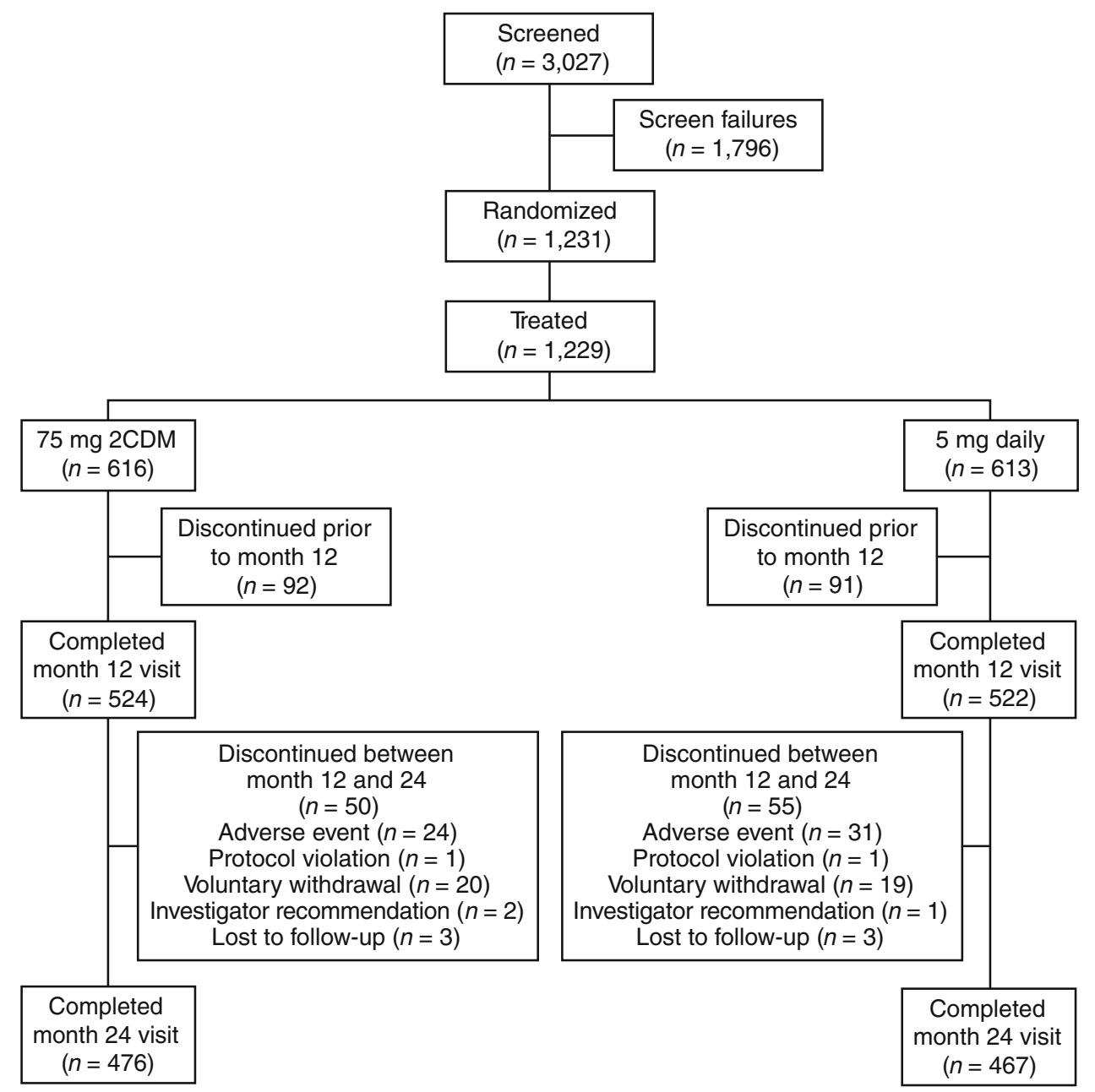

Table 1 Subject demographics at baseline

\begin{tabular}{lrr}
\hline Characteristic & $75 \mathrm{mg}$ 2CDM $(n=616)$ & $5 \mathrm{mg}$ daily $(n=613)$ \\
\hline Age (years), mean \pm SD & $65.1 \pm 7.80$ & $64.2 \pm 7.75$ \\
Lumbar spine BMD T-score, mean \pm SD & $-3.16 \pm 0.54$ & $-3.17 \pm 0.56$ \\
Total hip BMD T-score, mean \pm SD & $-1.91 \pm 0.77$ & $-1.86 \pm 0.78$ \\
uNTX/creatinine (nmol BCE/nmol), mean \pm SD & $60.8 \pm 39.9$ & $59.0 \pm 35.7$ \\
sBAP $(\mu \mathrm{g} / \mathrm{ml})$, mean \pm SD & $15.13 \pm 5.15$ & $15.01 \pm 5.37$
\end{tabular}

$B M D$ bone mineral density, $2 C D M$ two consecutive days each month, $s B A P$ serum bone-specific alkaline phosphatase, $u N T X$ urinary $\mathrm{N}$-telopeptide

\section{Primary Efficacy}

As reported previously [8], both risedronate $75 \mathrm{mg} 2 \mathrm{CDM}$ and $5 \mathrm{mg}$ daily increased lumbar spine BMD at month 12 , and the results indicate that the $75 \mathrm{mg} 2 \mathrm{CDM}$ dosing regimen was noninferior to the $5 \mathrm{mg}$ daily dosing regimen (treatment difference $0.21 ; 95 \% \mathrm{CI}-0.19$ to 0.62 ). Consistent with these data, lumbar spine BMD at month 24 was increased in both treatment groups: $4.2 \pm 0.19$ and $4.3 \pm 0.19 \%$ in the $75 \mathrm{mg}$ $2 \mathrm{CDM}$ and $5 \mathrm{mg}$ daily groups, respectively, and at end point: $4.1 \pm 0.18$ and $4.2 \pm 0.18 \%$, respectively (Fig. 2). The lumbar spine mean difference between treatment groups was 0.17 (95\% CI -0.35 to 0.68 ) at months 24 and $0.13(95 \% \mathrm{CI}-0.34$ to 0.60$)$ at end point. The upper bound 
of the $95 \%$ CI was less than the predefined noninferiority margin of $2.0 \%$, demonstrating the $2 \mathrm{CDM}$ regimen to be noninferior to the daily regimen at 24 months and at end point.

Table 2 Subject withdrawal by month 24 and reasons for treatment discontinuation

\begin{tabular}{lcc}
\hline Reason & $\begin{array}{l}75 \mathrm{mg} \mathrm{2CDM}, n(\%) \\
(n=616)\end{array}$ & $\begin{array}{l}5 \mathrm{mg} \text { daily, } n(\%) \\
(n=613)\end{array}$ \\
\hline $\begin{array}{l}\text { Discontinued before } \\
\text { month 24 }\end{array}$ & $142(23.0)$ & $146(23.8)$ \\
$\begin{array}{l}\text { Adverse event } \\
\text { Protocol violation }\end{array}$ & $80(13.0)$ & $86(14.0)$ \\
$\begin{array}{l}\text { Voluntary } \\
\text { withdrawal }\end{array}$ & $43(1.0)$ & $2(0.3)$ \\
$\begin{array}{l}\text { Investigator } \\
\text { recommendation }\end{array}$ & $7(1.1)$ & $45(7.3)$ \\
\begin{tabular}{l} 
Lost to follow-up \\
\hline
\end{tabular} & $6(1.0)$ & $7(1.1)$ \\
\hline
\end{tabular}

$2 C D M$ two consecutive days each month

Fig. 2 LS mean $( \pm$ SE) percentage change from baseline in a lumbar spine and b total hip BMD by visit. $2 C D M$ two consecutive days each month, $B M D$ bone mineral density, $L S$ least squares
Secondary Efficacy

There were no statistically significant differences between treatment groups for any of the secondary efficacy parameters at month 24 or end point, which included change from baseline in total hip (Fig. 2), femoral neck, and trochanter BMD (Table 3), and uNTx and sBAP (Fig. 3). At end point, 16 (2.9\%) patients treated with $75 \mathrm{mg} 2 \mathrm{CDM}$ and $15(2.7 \%)$ patients treated with $5 \mathrm{mg}$ daily had experienced 1 or more new morphometric vertebral fractures.

Safety

After 24 months, subjects in both treatment groups experienced comparable percentages of treatment-emergent adverse events (TEAEs) (Table 4). The overall proportion of subjects who withdrew from the study as a result of TEAEs was similar in the two treatment groups, comprising $12.8 \%$ of the subjects in the $75 \mathrm{mg} 2 \mathrm{CDM}$ group and
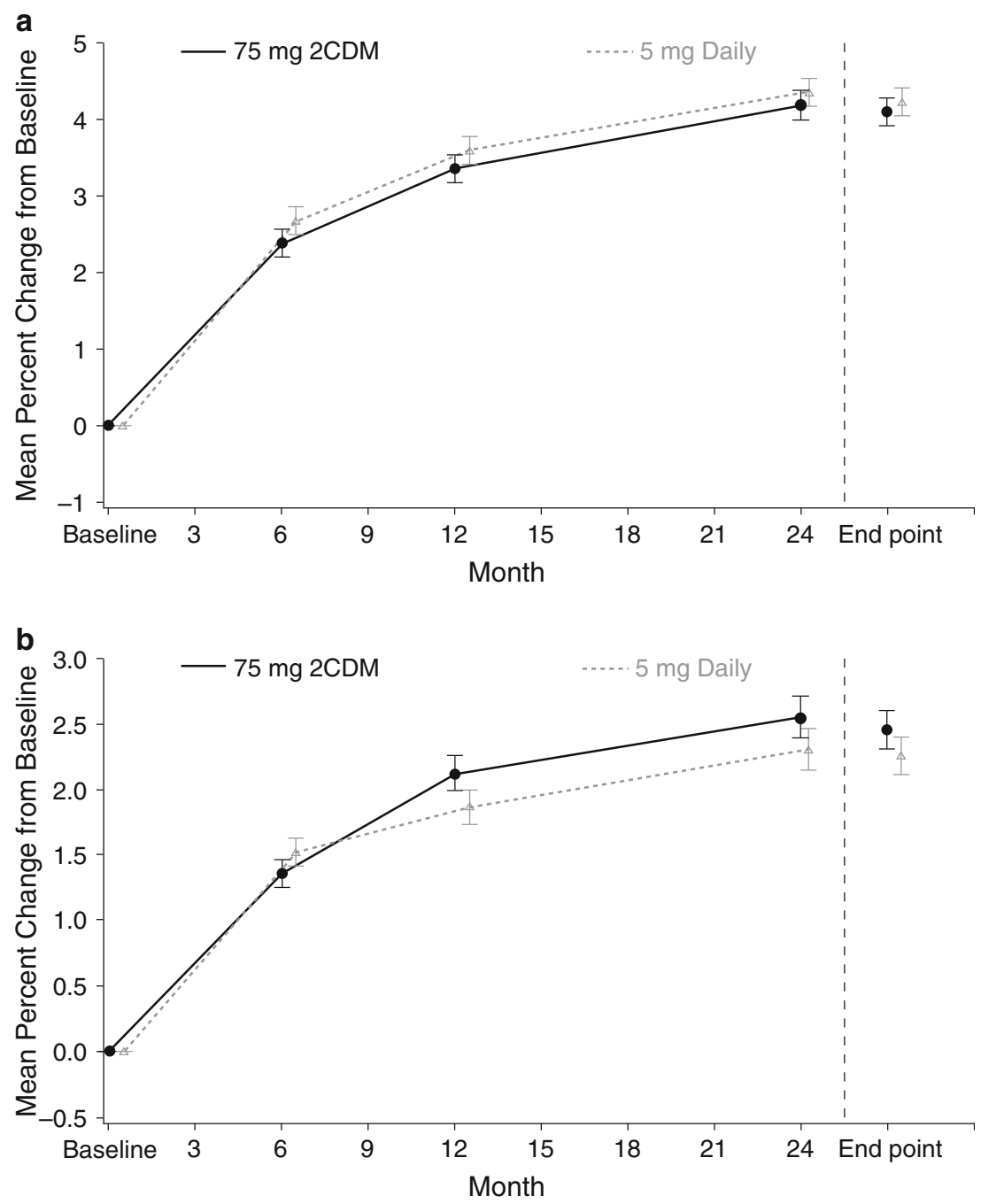
Table 3 Mean percentage change from baseline in BMD in the ITT population

\begin{tabular}{|c|c|c|c|c|c|}
\hline \multirow[t]{2}{*}{ Characteristic } & \multicolumn{2}{|c|}{$75 \mathrm{mg} 2 \mathrm{CDM}$} & \multicolumn{2}{|c|}{$5 \mathrm{mg}$ daily } & \multirow{2}{*}{$\begin{array}{l}5 \mathrm{mg} \text { daily }-75 \mathrm{mg} 2 \mathrm{CDM}, \mathrm{LS} \\
\text { mean difference }(95 \% \mathrm{CI})^{\mathrm{a}}\end{array}$} \\
\hline & $n$ & LS mean & $n$ & LS mean & \\
\hline \multicolumn{6}{|l|}{ Lumbar spine BMD } \\
\hline Baseline $\left(\mathrm{g} / \mathrm{cm}^{2}\right)$ & 615 & 0.742 & 613 & 0.744 & \\
\hline \multicolumn{6}{|c|}{ Percentage change from baseline } \\
\hline Month 6 & 544 & $2.385^{*}$ & 549 & $2.672 *$ & $0.287(-0.089 ; 0.662)$ \\
\hline Month 12 & 527 & $3.361^{*}$ & 531 & $3.588^{*}$ & $0.227(-0.176 ; 0.630)$ \\
\hline Month 24 & 479 & $4.181^{*}$ & 474 & $4.348^{*}$ & $0.167(-0.345 ; 0.679)$ \\
\hline End point & 553 & $4.102^{*}$ & 552 & $4.232 *$ & $0.130(-0.341 ; 0.600)$ \\
\hline \multicolumn{6}{|l|}{ Total hip BMD } \\
\hline Baseline $\left(\mathrm{g} / \mathrm{cm}^{2}\right)$ & 600 & 0.734 & 601 & 0.741 & \\
\hline \multicolumn{6}{|c|}{ Percentage change from baseline } \\
\hline Month 6 & 542 & $1.364^{*}$ & 551 & $1.522 *$ & $0.158(-0.141$ to 0.457$)$ \\
\hline Month 12 & 516 & $2.121^{*}$ & 522 & $1.862 *$ & $-0.259(-0.603$ to 0.085$)$ \\
\hline Month 24 & 468 & $2.549^{*}$ & 462 & $2.307^{*}$ & $-0.243(-0.657$ to 0.171$)$ \\
\hline End point & 553 & $2.457^{*}$ & 558 & $2.255^{*}$ & $-0.202(-0.577$ to 0.173$)$ \\
\hline \multicolumn{6}{|l|}{ Femoral neck BMD } \\
\hline Baseline $\left(\mathrm{g} / \mathrm{cm}^{2}\right)$ & 600 & 0.665 & 601 & 0.670 & \\
\hline \multicolumn{6}{|c|}{ Percentage change from baseline } \\
\hline Month 6 & 542 & $1.039^{*}$ & 551 & $0.800^{*}$ & $-0.238(-0.603$ to 0.126$)$ \\
\hline Month 12 & 516 & $1.615^{*}$ & 522 & $1.145^{*}$ & $-0.470(-0.894$ to -0.047$)$ \\
\hline Month 24 & 468 & $1.981^{*}$ & 462 & $1.677^{*}$ & $-0.304(-0.852$ to 0.243$)$ \\
\hline End point & 553 & $1.948^{*}$ & 558 & $1.576^{*}$ & $-0.372(-0.864$ to 0.121$)$ \\
\hline \multicolumn{6}{|c|}{ Femoral trochanter BMD } \\
\hline Baseline $\left(\mathrm{g} / \mathrm{cm}^{2}\right)$ & 600 & 0.570 & 601 & 0.573 & \\
\hline \multicolumn{6}{|c|}{ Percentage change from baseline } \\
\hline Month 6 & 542 & $2.081^{*}$ & 551 & $2.424 *$ & $0.344(-0.150$ to 0.837$)$ \\
\hline Month 12 & 516 & $2.971^{*}$ & 522 & $3.022 *$ & $0.051(-0.494$ to 0.595$)$ \\
\hline Month 24 & 468 & $3.957^{*}$ & 462 & $3.870^{*}$ & $-0.087(-0.741$ to 0.567$)$ \\
\hline End point & 553 & $3.809^{*}$ & 558 & $3.796^{*}$ & $-0.013(-0.603$ to 0.577$)$ \\
\hline
\end{tabular}

Consists of ITT subjects with analyzable baseline and postbaseline data for the relevant visit

ANOVA analysis of variance, $B M D$ bone mineral density, $2 C D M$ two consecutive days each month, $C I$ confidence interval (2-sided), ITT intention to treat, $L S$ least squares, $n$ number of subjects in the indicated population with values at baseline and the relevant visit

* Statistically significant difference from baseline determined from a $95 \%$ CI unadjusted for multiple comparisons

a Adjusted means, mean differences, and confidence intervals are from an ANOVA model containing treatment and pooled investigative center

$13.9 \%$ in the $5 \mathrm{mg}$ daily group. Nine deaths occurred during the 24 months of the study: three in the $75 \mathrm{mg}$ $2 \mathrm{CDM}$ group and six in the $5 \mathrm{mg}$ daily group. None of the deaths were considered to be treatment-related. A comparable proportion of subjects in both groups experienced musculoskeletal TEAEs and upper gastrointestinal TEAEs. No reports of fever or influenza-like illness, potentially representing acute phase reactions, occurred in year 2 of the study. No case of atypical femoral fracture or osteonecrosis of the jaw (ONJ) was identified in our study.

The incidence of clinical vertebral and nonvertebral fracture TEAEs were similar in the two treatment groups (Table 4). It should be noted, however, that this study was not statistically powered to detect differences in fracture rates as efficacy outcome measures.

\section{Discussion}

Although a $5 \mathrm{mg}$ daily risedronate dosing regimen was developed initially, less frequent dosing regimens with similar efficacy and safety profiles are now available. This study demonstrated that risedronate $75 \mathrm{mg} 2 \mathrm{CDM}$ is noninferior to the $5 \mathrm{mg}$ daily regimen in postmenopausal women with osteoporosis after 24 months of treatment. These data are consistent with the noninferiority of the 

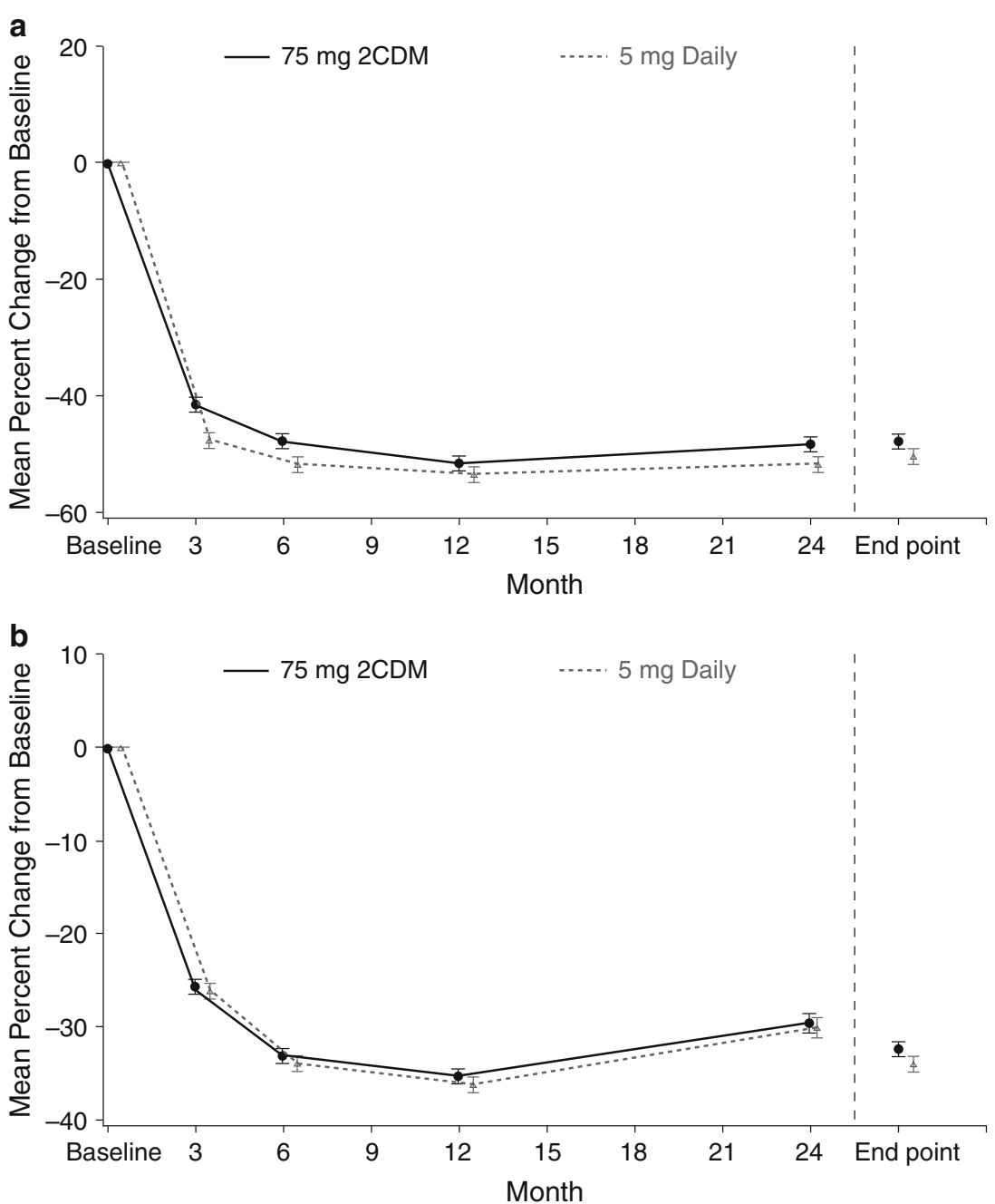

Fig. 3 LS mean $( \pm \mathrm{SE})$ percentage change from baseline in a uNTX/creatinine and b sBAP. $2 C D M$ two consecutive days each month, $s B A P$ serum bone-specific alkaline phosphatase, $u N T X$ urinary $\mathrm{N}$-telopeptide

2CDM dose compared to the daily dosing regimen reported in the interim analysis after 12 months of therapy [8]. The smaller increase in BMD during the second year of therapy $(0.8 \%)$ compared with the $3.4 \%$ observed during the first year of treatment is consistent with previous risedronate studies $[4,5]$. This pattern of BMD response is typical of that observed with all antiresorptive agents and does not connote loss of efficacy after the first year. Additionally, comparison of the BMD response at the end of the first and second years of treatment is complicated because not all subjects included in the month 12 results continued to be included in the month 24 analysis. Secondary efficacy analyses also showed no differences between the $75 \mathrm{mg}$ $2 \mathrm{CDM}$ and the $5 \mathrm{mg}$ daily regimens with respect to BMD at the proximal femur or in bone turnover markers.

Overall, the safety profile and tolerability of risedronate $75 \mathrm{mg} 2 \mathrm{CDM}$ over 24 months of therapy was similar to that of the $5 \mathrm{mg}$ daily regimen. In particular, comparable percentages of musculoskeletal and upper gastrointestinal TEAEs were found across treatment groups. Although infrequent mild or moderate acute phase reactions were observed at the beginning of therapy in the $75 \mathrm{mg} 2 \mathrm{CDM}$ group [8], there was no reported incidence of these symptoms during year 2 . This is similar to the pattern of acute phase reactions that occurs with intravenous bisphosphonates where symptoms primarily occur after the initial dose [9].

These data are consistent with previous studies that have demonstrated favorable tolerability and safety profiles with risedronate, independent of dosing regimen [4, 5, 7, 10-14]. Additionally, in clinical trials, long-term treatment with risedronate does not increase the incidence of adverse events, including upper gastrointestinal complaints $[15,16]$. Concern exists about skeletal safety with long term bisphosphonate therapy. No case of ONJ or atypical femoral fractures has been identified in our study or any of the 
Table 4 Overview of TEAEs (safety population)

\begin{tabular}{lll}
\hline Characteristic & $75 \mathrm{mg} 2 \mathrm{CDM}, n(\%)(n=616)$ & $5 \mathrm{mg}$ daily, $n(\%)(n=613)$ \\
\hline Subjects with TEAEs & $561(91.1)$ & $551(89.9)$ \\
Subjects with serious TEAEs & $89(14.4)$ & $66(10.8)$ \\
Subjects withdrawn as a result of a TEAE & $79(12.8)$ & $85(13.9)$ \\
Subjects with TEAEs resulting in death & $3(0.5)$ & $6(1.0)$ \\
AEs of special interest & $162(26.3)$ & $169(27.6)$ \\
Subjects with upper GI TEAEs & $59(9.6)$ & $53(8.6)$ \\
Subjects with moderate to severe upper GI TEAEs & $4(0.7)$ & 0 \\
Subjects with acute phase reaction ${ }^{\text {a }}$ & $16(2.9)$ & $15(2.7)$ \\
Subjects with $\geq 1$ morphometric vertebral fracture & $6(1.0)$ & $5(0.8)$ \\
Subjects with clinical vertebral fracture & $6(1.0)$ & $5(0.8)$ \\
Subjects with vertebral clinical fracture TEAEs & $35(5.7)$ & $31(5.1)$ \\
Subjects with nonvertebral clinical fracture TEAEs & $21(3.4)$ & $13(2.1)$ \\
Subjects with osteoporosis-related fractures TEAEs ${ }^{\mathrm{b}}$ & $190(30.8)$ & $187(30.5)$ \\
Subjects with selected musculoskeletal TEAEs & &
\end{tabular}

Safety population includes subjects who were randomized to the treatment groups and received $\geq 1$ documented dose of investigational product $A E$ adverse event, $2 C D M$ two consecutive days each month, GI gastrointestinal, ITT intent to treat, TEAE treatment-emergent adverse event

${ }^{a}$ Includes fever and influenza-like illness during first 5 days of treatment

b Includes fractures at wrist, hip, leg, clavicle, humerus, and pelvis

Phase 3 risedronate clinical trials that comprise more than 25,000 patient-years of exposure. However, fewer than 200 patients were followed for more than 5 years [16].

The noninferiority of the $75 \mathrm{mg} 2 \mathrm{CDM}$ dose demonstrated at month 24 are consistent with the results of the 1 -year interim report [8]. These are not unexpected findings because the $75 \mathrm{mg} 2 \mathrm{CDM}$ dosing regimen represents the same cumulative monthly dose of risedronate $(150 \mathrm{mg})$ as the $5 \mathrm{mg}$ daily dosing regimen, and a previous study showed that plasma blood levels and pharmacokinetic parameters are linear between the $5 \mathrm{mg}$ daily dose and the $75 \mathrm{mg} 2 \mathrm{CDM}$ [17]. Additionally, the response to risedronate given as a single dose of $150 \mathrm{mg}$ monthly is similar to that of the $5 \mathrm{mg}$ daily dose [11]. Although no direct comparison has been made between the $75 \mathrm{mg} 2 \mathrm{CDM}$ dose and the $150 \mathrm{mg}$ once monthly dose of risedronate, the clinical responses with the $2 \mathrm{CDM}$ regimen at month 24 are similar to the responses observed with risedronate $150 \mathrm{mg}$ given once monthly as a single tablet. After 2 years, the mean increase in lumbar spine BMD from baseline was $4.2 \%$ with the $2 \mathrm{CDM}$ dose. That same metric was $3.9 \%$ with the $5 \mathrm{mg}$ daily dose and $4.2 \%$ with the $150 \mathrm{mg}$ once monthly dose in a previous study [18].

A limitation of this study is that the primary efficacy measure was BMD rather than vertebral and nonvertebral fracture risk. However, the occurrence of new vertebral fractures was a secondary efficacy measure, and there was no difference between groups in this parameter at 12 and 24 months. Relative to the historical placebo group, the risk of vertebral fracture at month 12 with the $75 \mathrm{mg}$
2CDM dose of risedronate was reduced by $79 \%(5.1 \%$ in historical placebo group vs. $1.1 \%$ in the risedronate $75 \mathrm{mg}$ $2 \mathrm{CDM}$ group; relative risk $=0.21 ; 95 \% \mathrm{CI} 0.05$ to 0.88 ; $p=0.016$ ) [19]. The US Food and Drug Administration (FDA) and the European Agency for the Evaluation of Medicinal Products guidelines have determined that alternate dose forms can be approved based upon BMD for a bisphosphonate that has established fracture risk reduction [20].

Preference among osteoporosis treatment options is mainly influenced by fracture efficacy, tolerability, and convenience of the dosing regimen [21, 22]. As has been demonstrated with once weekly and once monthly dosing forms of risedronate, risedronate $75 \mathrm{mg} 2 \mathrm{CDM}$ has an efficacy and safety profile similar to the $5 \mathrm{mg}$ daily regimen over 2 years [10, 18]. The once-a-month dose is available in some, but not all, countries. For patients without access to once-a-month risedronate, the 2CDM treatment regimen offers an additional treatment option for women with postmenopausal osteoporosis who prefer a monthly dosing regimen of a drug proven to reduce the risk of vertebral and nonvertebral fractures.

In conclusion, risedronate $75 \mathrm{mg} 2 \mathrm{CDM}$ is noninferior to the $5 \mathrm{mg}$ daily dosing regimen after 2 years of treatment in women with postmenopausal osteoporosis. This dosing regimen is as safe and well tolerated as the $5 \mathrm{mg}$ daily dosing regimen. Risedronate $75 \mathrm{mg} 2 \mathrm{CDM}$ provides a more convenient dosing schedule with a bisphosphonate that has proven fracture reduction efficacy at both vertebral and nonvertebral sites, including those of the hip $[4,6]$. 
Acknowledgments Funding for this study was provided by Warner Chilcott Pharmaceuticals Inc., and Sanofi. The authors received editorial/writing support in the preparation of this article, funded by Warner Chilcott Pharmaceuticals Inc., and Sanofi. Tam Vo, PhD, from Excerpta Medica provided editorial and writing assistance. The authors are fully responsible for all content, editorial decisions, and opinions expressed in this study. The authors received no form of compensation related to the development of this article.

Open Access This article is distributed under the terms of the Creative Commons Attribution License which permits any use, distribution, and reproduction in any medium, provided the original author(s) and the source are credited.

\section{References}

1. Emkey R, Koltun W, Beusterien K, Seidman L, Kivitz A, Devas V, Masanauskaite D (2005) Patient preference for once-monthly ibandronate versus once-weekly alendronate in a randomized, open-label, cross-over trial: the Boniva Alendronate Trial in Osteoporosis (BALTO). Curr Med Res Opin 21:1895-1903

2. Recker RR, Gallagher R, MacCosbe PE (2005) Effect of dosing frequency on bisphosphonate medication adherence in a large longitudinal cohort of women. Mayo Clin Proc 80:856-861

3. Cooper A, Drake J, Brankin E, PERSIST Investigators (2006) Treatment persistence with once-monthly ibandronate and patient support vs once-weekly alendronate: results from the PERSIST study. Int J Clin Pract 60:896-905

4. Harris ST, Watts NB, Genant HK, McKeever CD, Hangartner T, Keller M, Chesnut CH 3rd, Brown J, Eriksen EF, Hoseyni MS, Axelrod DW, Miller PD, Vertebral efficacy with risedronate therapy (VERT) study group (1999) Effects of risedronate treatment on vertebral and nonvertebral fractures in women with postmenopausal osteoporosis: a randomized controlled trial. JAMA 282:1344-1352

5. Reginster J, Minne HW, Sorensen OH, Hooper M, Roux C, Brandi ML, Lund B, Ethgen D, Pack S, Roumagnac I, Eastell R, Vertebral efficacy with risedronate therapy (VERT) study group (2000) Randomized trial of the effects of risedronate on vertebral fractures in women with established postmenopausal osteoporosis. Osteoporos Int 11:83-91

6. McClung MR, Geusens P, Miller PD, Zippel H, Bensen WG, Roux C, Adami S, Fogelman I, Diamond T, Eastell R, Meunier PJ, Reginster JY, Hip intervention program study group (2001) Effect of risedronate on the risk of hip fracture in elderly women. N Engl J Med 344:333-340

7. Brown JP, Kendler DL, McClung MR, Emkey RD, Adachi JD, Bolognese MA, Li Z, Balske A, Lindsay R (2002) The efficacy and tolerability of risedronate once a week for the treatment of postmenopausal osteoporosis. Calcif Tissue Int 71:103-111

8. Delmas PD, Benhamou CL, Man Z, Tlustochowicz W, Matzkin E, Eusebio R, Zanchetta J, Olszynski WP, Recker RR, McClung MR (2008) Monthly dosing of $75 \mathrm{mg}$ risedronate on 2 consecutive days a month: efficacy and safety results. Osteoporos Int 19:1039-1045
9. Reid IR, Gamble GD, Mesenbrink P, Lakatos P, Black DM (2010) Characterization of and risk factors for the acute-phase response after zoledronic acid. J Clin Endocrinol Metab 95:4380-4387

10. Harris ST, Watts NB, Li Z, Chines AA, Hanley DA, Brown JP (2004) Two-year efficacy and tolerability of risedronate once a week for the treatment of women with postmenopausal osteoporosis. Curr Med Res Opin 20:757-764

11. Delmas PD, McClung MR, Zanchetta JR, Racewicz A, Roux C, Benhamou CL, Man Z, Eusebio RA, Beary JF, Burgio DE, Matzkin E, Boonen S (2008) Efficacy and safety of risedronate $150 \mathrm{mg}$ once a month in the treatment of postmenopausal osteoporosis. Bone 42:36-42

12. Miller PD, Roux C, Boonen S, Barton IP, Dunlap LE, Burgio DE (2005) Safety and efficacy of risedronate in patients with agerelated reduced renal function as estimated by the Cockcroft and Gault method: a pooled analysis of nine clinical trials. J Bone Miner Res 20:2105-2115

13. Karam R, Camm J, McClung M (2007) Yearly zoledronic acid in postmenopausal osteoporosis. N Engl J Med 357:712-713

14. Watts NB, Chines A, Olszynski WP, McKeever CD, McClung MR, Zhou X, Grauer A (2008) Fracture risk remains reduced one year after discontinuation of risedronate. Osteoporos Int 19:365-372

15. Sorensen $\mathrm{OH}$, Crawford GM, Mulder H, Hosking DJ, Gennari C, Mellstrom D, Pack S, Wenderoth D, Cooper C, Reginster JY (2003) Long-term efficacy of risedronate: a 5-year placebo-controlled clinical experience. Bone 32:120-126

16. Mellström DD, Sörensen OH, Goemaere S, Roux C, Johnson TD, Chines AA (2004) Seven years of treatment with risedronate in women with postmenopausal osteoporosis. Calcif Tissue Int 75:462-468

17. Thompson GA, Russell DA, Schnell DJ, Burgio DE, Sun LA (2006) Risedronate pharmacokinetics following daily and monthly dosing regimes. Calcif Tissue Int 78(suppl 1):S162

18. McClung MR, Zanchetta JR, Racewicz A, Roux C, Benhamou CL, Man Z, Eusebio RA, Beary JF, Burgio DE, Matzkin E, Boonen S, Delmas P (2012) Efficacy and safety of risedronate $150-\mathrm{mg}$ once a month in the treatment of postmenopausal osteoporosis: 2-year data. Osteoporos Int [Epub ahead of print]

19. Watts NB, Brown JP, Cline G (2010) Risedronate on 2 consecutive days a month reduced vertebral fracture risk at 1 year compared with historical placebo. J Clin Densitom 13:56-62

20. EMEA Committee for Medicinal Products for Human Use (2006) Guideline on the evaluation of medicinal products in the treatment of primary osteoporosis. http://www.emea.europa.eu/pdfs/human/ ewp/55295enfin.pdf. Accessed Jan 2010

21. Gold DT, Safi W, Trinh H (2006) Patient preference and adherence: comparative US studies between two bisphosphonates, weekly risedronate and monthly ibandronate. Curr Med Res Opin 22:2383-2391

22. Keen R, Jodar E, Iolascon G, Kruse HP, Varbanov A, Mann B, Gold DT (2006) European women's preference for osteoporosis treatment: influence of clinical effectiveness and dosing frequency. Curr Med Res Opin 22:2375-2381 